\title{
Erişkin bir hastada pulmoner sekestrasyon
}

\author{
Pulmonary sequestration in an adult patient \\ Cihat Pınarcı ${ }^{1}$ Selen Bayraktaroğlu ${ }^{1}$ Özge Can $^{2}$ \\ ${ }^{1}$ Ege Üniversitesi Tıp Fakültesi Radyoloji Anabilim Dalı, İzmir, Türkiye \\ ${ }^{2}$ Ege Üniversitesi Acil Tıp Anabilim Dalı, Bornova, İzmir, Türkiye
}

\section{ÖZ}

Pulmoner sekestrasyon, nadiren erişkinlerde gözlenen konjenital bir akciğer malformasyonudur. Genellikle erken çocukluk çağında tanı konulur. Intra ve ekstralobar olmak üzere iki tipi vardır. Tanıda en önemli bulgu, sistemik arteryal sistemden köken alan arteri ve pulmoner veya sistemik venlere drene olan bir venöz yapısı olmasıdır. BT bulguları erişkin yaş grubunda pnömoni ya da kitle ile karışabilmektedir. Tanı için tipik lokalizasyon ve besleyici vasküler yapının BT anjiyografik demonstrasyonu önemlidir.

Anahtar Sözcükler: Pulmoner sekestrasyon, erişkin, intralobar.

\section{ABSTRACT}

Pulmonary sequestration is a congenital lung malformation that is rarely observed in adults. It is usually diagnosed in early childhood. There are two types, intra and extra lobar. The most important finding in diagnosis is the artery originating from the systemic arterial system and a venous structure that drains into the pulmonary or systemic veins. CT findings can be confused with pneumonia or a mass in the adult age group. CT angiographic demonstration of typical localization and nutrient vascular structure is important for diagnosis.

Keywords: Pulmonary sequestration, adult, intra lobar.

\section{OLGU}

Bilinen ek hastalığı bulunmayan 39 yaşında erkek hasta, araç içi trafik kazası nedeniyle hastaneye başvurdu. Klinik değerlendirmede travma ile ilişkili bulgular saptanmış olup vital bulguları ve laboratuvar testlerinde patoloji izlenmedi. Akciğer grafisinde, retrokardiyak alanda kitle imajı veren lezyon izlendi (Şekil-1). Hastanın tüm vücut kontrastlı Bilgisayarlı Tomografi (BT) tetkikinde travmadan bağımsız, sol akciğer alt lob posterior bazal segmentte, düzgün ancak lobüle kontürlü, homojen iç yapıda
$7 \mathrm{~cm}$ boyutunda kitlesel lezyon izlendi. Lezyonun akciğere bası etkisi yaratmadığı, çevre dokularda destrüksiyon oluşturmadığı gözlendi. Lezyonun torasik aorttan köken alan arteriyel bir yapı ile kanlanma gösterdiği (Şekil-2) ve sol inferior pulmoner vene dökülen bir vene sahip olduğu izlendi (Şekil-3A).

Lezyona komşu akciğer parankiminde fokal hiperlüsen alanlar mevcuttu (Şekil-3B). Bu bulgular eşliğinde intralobar pulmoner sekestrasyon tanısı konuldu. Pulmoner venlerde, venöz dönüş anomalisi saptanmadı.

\footnotetext{
Sorumlu yazar: Cihat Pınarcı

Ege Üniversitesi Tıp Fakültesi Radyoloji Anabilim Dalı, İzmir, Türkiye

E-posta: cihat.pinarci12@gmail.com

Başvuru tarihi: 29.12.2020 Kabul tarihi: 01.03.2021
} 


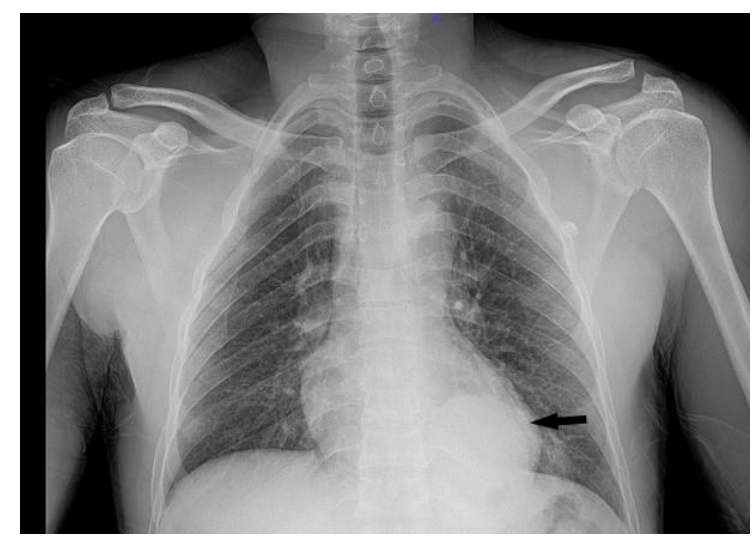

Şekil-1. PA akciğer grafisi: Solda, kalp silueti üzerine süperpoze görünümde, kalp konturunu silmeyen lobule görünümlü retrokardiyak opasite izlenmekte (Siyah ok).

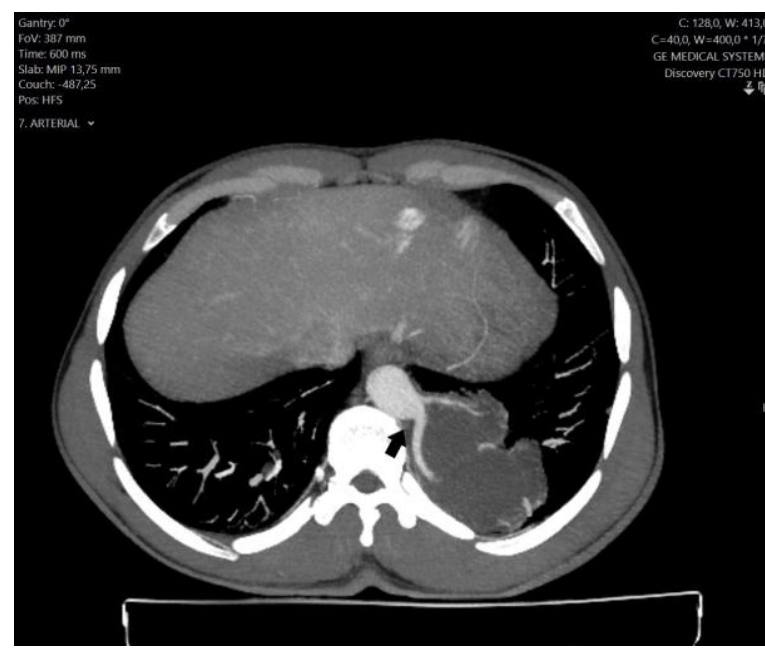

Şekil-2. Kontrastlı BT incelemede, aksial planda MIP görüntüde, sol akciğer alt lobda, lobüle kontürlü düzgün sınırlı lezyon izlenmekte. Desendan torasik aorttan çıkarak lezyona uzanan vasküler yapıya dikkat ediniz (siyah ok).

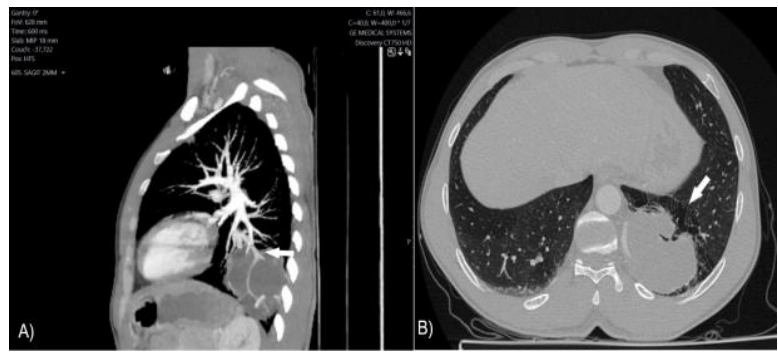

Şekil-3. A. Aynı seviyeden geçen kesitte MIP görüntüde sagittal planda kitle imajı veren lezyon izlenmektedir. Sol inferior pulmoner vene dökülen venöz yapıya dikkat ediniz (beyaz ok). B: Akciğer parankim penceresinde lezyon komşuluğunda hiperlüsensi gösteren alanlar izlenmektedir (Beyaz ok).
Yirmi yıl önce bir kez pnömoni tanısı ile yatarak tedavi gördüğünü belirten hasta tekrarlayan enfeksiyon öyküsü bildirmedi. Tanı ardından hasta takibe alındı.

Pulmoner sekestrasyon, trakeobronşial sistem ile bağlantısı bulunmayan, sistemik arteriyel dolaşımdan anormal kanlanma gösteren, displastik akciğer dokusu içeren, konjenital bir akciğer malformasyonudur (1). Etiyolojisi tartışmalı olmakla birlikte, embriyonik gelişim sürecinde, normal akciğer tomurcuklarının kaudalinde, anormal gelişen aksesuar bir tomurcuğun neden olduğu kabul görmektedir (2). İntralobar (ILS) ve ekstralobar sekestrasyon (ELS) olmak üzere iki gruba ayrılırlar. ILS daha sık gözlenmekte olup fonksiyonel akciğer dokusunun visseral plevrası içerisinde bulunur (1, 3). Genellikle tanı erken pediatrik yaş grubunda konulur ve erişkinlerde oldukça nadir gözlenir. Literatürde tüm pulmoner malformasyonların $\% 0,15-6,4$ 'ünde pulmoner sekestrasyon gözlendiği bildirilmektedir (3). Sıklıkla sol alt lobda saptanır ve venöz dönüşü pulmoner ven ile sağlanır (1). ELS normal akciğerden ayrı bir visseral plevra içerir ve pulmoner venler yanı sıra azigos ve hemiazigos gibi sistemik venlere de drene olabilir (3). Arteriyel desteği, hastaların büyük bir kısmında torasik aorttan sağlanır (2). Ayrıca abdominal aorta, süperior mezenterik arter, hepatik arter ve çölyak trunkus gibi vasküler yapılardan da köken alan sekestrasyon örnekleri bildirilmiştir (3). Her iki grupta da tanı genellikle çocukluk çağında konulur (2). Adölesan ve erken erişkinlik döneminde karşılaşılan hastaların büyük kısmında tekrarlayan enfeksiyonlar saptanır (4). Bunun dışında öksürük, göğüs ağrısı, dispne, ateş şikâyetleri bulunabileceği gibi hastalar asemptomatik de olabilirler (5). Görüntülemede akciğer grafisinde en sık gözlenen lezyonlar soliter nodül ya da kitle, tek ya da multiloküle kist veya konsolidasyondur (4). Tanıda BT tetkiki hem parankimi hem de vasküler yapıları göstermesi bakımından oldukça değerlidir. BT bulguları genellikle, kitle, homojen ya da heterojen konsolidasyon veya Sıvı ya da hava içeren kistler şeklinde tanımlanır (4.5). Kontrastlı tetkiklerde sistemik dolaşımdan köken alan besleyici arter ve pulmoner veya sistemik venlere drene olan venin gösterilmesi önemlidir (4). Nadir olmayarak akciğer parankiminde hava hapsine sekonder 
hiperlüsensi izlenebilir (5). Ayırıcı tanıda, kistik adenomatoid malformasyon, bronkojenik kist, fokal bronşektazi, konjenital lobar amfizem ve ekstralobar abdominal sekestrasyonda retroperitoneal tümörler yer alır (1). Tedavi seçenekleri arasında torakotomik lobektomi ya da segmentektomi, video-yardımlı torakoskopik cerrahi (VATS) gibi yöntemler bulunmaktadır (3). İntralobar sekestrasyon erişkin yaş grubunda nadir olarak izlenen bir konjenital anomalidir. Özellikle sol akciğer alt lob yerleşimli tekrarlayan konsolidasyon öyküsü olan olgularda bu tanı göz önünde bulundurulmalıdır. BT anjiyografik değerlendirme ile besleyici anormal damarın demonstrasyonu tanıda önemlidir.

Çıkar çatışması: Herhangi bir çıkar çatışması bulunmamaktadır.

\section{Kaynaklar}

1. Chakraborty RK, Modi P, Sharma S. Pulmonary Sequestration. [Updated 2020 Jul 26]. In: StatPearls [Internet]. Treasure Island (FL): StatPearls Publishing; 2020 Jan-. Available from: https://www.ncbi.nlm.nih.gov/books/NBK532314/

2. Corbett HJ, Humphrey GM. Pulmonary sequestration. Paediatr Respir Rev. 2004; 5 (1): 59-68.

3. Zhang N, Zeng Q, Chen C, Yu J, Zhang X. Distribution, diagnosis, and treatment of pulmonary sequestration: Report of 208 cases. J Pediatr Surg. 2019; 54 (7): 1286-92.

4. Walker CM, Wu CC, Gilman MD, Godwin JD 2nd, Shepard JA, Abbott GF. The imaging spectrum of bronchopulmonary sequestration. Curr Probl Diagn Radiol. 2014; 43 (3): 100-14.

5. Alsumrain M, Ryu JH. Pulmonary sequestration in adults: a retrospective review of resected and unresected cases. BMC Pulm Med. 2018; 5; 18 (1): 97. 